13,07

\title{
Скольжение как базовый механизм образования структурных элементов деформационного рельефа
}

\author{
(С) Д.В. Лычагин, Е.А. Алфёрова \\ Национальный исследовательский Томский политехнический университет, \\ Томск, Россия \\ Национальный исследовательский Томский государственный университет, \\ Томск, Россия \\ I E-mail: katerina525@mail.ru
}

(Поступила в Редакцию 29 ноября 2016 г.)

\begin{abstract}
Представлены экспериментальные результаты исследования морфологии поверхности монокристаллов никеля после деформации сжатием. Выявлен квазипериодический характер деформационного профиля, общий для организации сдвиговой деформации структурных элементов рельефа различного типа. Показано, что их морфологическое проявление обусловлено локально действующими системами сдвига по октаэдрическим плоскостям. Установлены закономерности организации деформации в этих областях, обусловливающие формирование областей экструзии и интрузии материала и особенности накопления разориентировки. В том случае, когда наряду с октаэдрическим скольжением в формировании элементов рельефа задействована переориентация локальных областей, наблюдается значительно большее увеличение площади поверхности. Рассмотрена возможность использования для описания деформационного рельефа дву- и трехмерных параметров шероховатости поверхности.
\end{abstract}

Исследование выполнено при финансовой поддержке РФФИ в рамках научного проекта № 16-32-60007 мол_а_дк.

DOI: 10.21883/FTT.2017.07.44606.427

\section{1. Введение}

Изменения морфологических параметров поверхности нагруженного тела уже долгие годы интересуют исследователей из разных областей. Экспериментальные результаты и данные математических моделей свидетельствуют о том, что складкообразование, гофрирование, шахматное распределение областей экструзии и интрузии и т. Д. являются характерными процессами при формировании деформационного рельефа и возникают при различных условиях нагружения в поли- и монокристаллах [1-10]. Складкообразование реализуется при разных способах деформации, имеет многообразные проявления и может быть инициировано как скольжением, так и двойникованием.

В настоящее время накоплен материал по математическому моделированию процессов формирования шероховатости поверхности в различных условиях нагружения $[1,2]$. В работе [1] методом конечных элементов было проведено моделирование процесса возникновения шероховатости при пластической деформации образцов поликристаллического алюминия. В ней показано, что в зависимости от текстуры образцов и вида нагружения наблюдается формирование шероховатости с „ребристым“ профилем (ribbed ridging profiles) и поверхности типа „апельсиновой корки“ (orange peel shape). В этой работе также указывается, что фактор Тейлора влияет на тип возникающей шероховатости. Влияние размера зерна на шероховатость поверхности выявлено также в [2].

Экспериментальные данные, полученные на поликристаллах алюминиевых сплавов и чистой меди, свидетель- ствуют о влиянии размера и ориентации зерен на шероховатость, возникающую после пластической деформации [3-5]. При этом во всех случаях наблюдается квазипериодический профиль поверхности после нагружения. Есть результаты, свидетельствующие о складкообразовании в сталях, деформирующихся двойникованием [6].

Существует цикл работ, в частности [7], в которых причиной гофрирования поверхности названо искажение слоев материала, а также показано, что гофр может формироваться и в структурно-однородном материале (монокристалл). Данный факт объясняется тем, что потеря устойчивости слоями материала возникает из-за наличия знакопеременных напряжений на мезоуровне деформации в условиях стесненного сдвига. В работе отмечается, что гофрирование является следствием градиента напряженно-деформированного состояния по сечению образца и стесненности деформации слоев материала в очаге деформации.

Процесс формирования складок, шахматного распределения областей экструзии и интрузии рассматривался с точки зрения физической мезомеханики $[8,9]$. В рамках этого подхода обоснована многомасштабность процесса, установлена связь с границами раздела разнообразной природы, а поверхностный слой рассматривается как самостоятельный структурный уровень деформации.

Таким образом, накопленный экспериментальный и теоретический материал позволяет сделать заключение о том, что формирование квазипериодического профиля изначально плоской поверхности является характерным процессом при деформировании материалов разными 
способами. Причины этого процесса могут быть различными. В настоящее время в литературе обсуждаются различные обстоятельства его происхождения.

В своих более ранних исследованиях авторы не раз указывали на квазипериодический профиль поверхности монокристаллов после пластической деформации и периодичность распределения величин деформации (в том числе на чередование локальных мест растяжения и сжатия) [11-13]. Одновременно мы исследовали отличительные особенности морфологии, характерные для различных типов структурных элементов деформационного рельефа.

Вместе с тем актуальным остается вопрос о количественной оценке изменений деформационного рельефа во взаимосвязи с его качественной стороной (морфологическими особенностями). Наряду с индивидуальными параметрами рельефа (расстоянием между следами, высотой ступенек сдвига, геометрическими размерами мезоскопических структурных элементов) представляет интерес использовать различные параметры рельефа, которые нашли свое отражение в интегральных, амплитудных и гибридных характеристиках шероховатости поверхности.

Настоящая работа является составной частью исследований по выявлению закономерностей организации деформационного рельефа на поверхности ГЦК-монокристаллов. Она направлена на дальнейшее изучение морфологии поверхности монокристаллов после пластической деформации с целью установления способов формирования структурных элементов деформационного рельефа различного типа и их количественного описания.

\section{2. Материал и методика}

В работе описываются результаты, полученные на монокристаллах никеля с ориентацией осей сжатия в углах стандартного стереографического треугольника с разными наборами боковых граней. Образцы имели форму тетрагональной призмы с отношением высоты к ширине, равным двум.

Исследования проводились в интервале степеней деформации от 3 до 31\%. Деформирование сжатием осуществлялось на испытательной машине Instron ElektroPuls E10000 со скоростью $1.4 \cdot 10^{-3} \mathrm{~s}^{-1}$ при комнатной температуре. Картина деформационного рельефа исследовалась на оптическом микроскопе Leica DM 2500 Р и конфокальном лазерном сканирующем микроскопе Olympus LEXT OLS4100.

Для оценки деформационного рельефа в работе использовался дву- и трехмерный анализ шероховатости поверхности. Каждый из этих методов вносит свой вклад в понимание процесса самоорганизации деформационного рельефа.

Двумерный анализ применялся для идентификации ступеней сдвига. Кроме того, был рассчитан параметр $R_{\mathrm{sk}}$ - асимметрия высотного распределения профиля (ГОСТ Р ИСО 4287-2014, ISO 4287: 1997).
Трехмерная оценка дает количественные параметры структуры того или иного типа, занимающей определенную площадь грани. В связи с тем что в данном случае оценивается не отдельный срез, а вся поверхность, она более точна и надежна. Кроме того, трехмерный анализ позволяет визуализировать поверхность для получения дополнительной информации по организации рельефа.

Для трехмерной оценки поверхности в работе использовались следующие параметры (ГОСТ Р ИСО 25178-2-2014, ИСО 25178-2:2012): $S_{\text {а }}$ - арифметическое среднее высоты поверхности ограниченного масштаба, $S_{\mathrm{q}}$ - среднее квадратичное значение высоты поверхности ограниченного масштаба, $S_{\mathrm{sk}}-$ асимметрия поверхности ограниченного масштаба, $S_{\mathrm{ku}}-$ эксцесс поверхности ограниченного масштаба.

Значения перечисленных выше параметров получены для поверхности, занятой структурными элементами деформационного рельефа различного типа, площадью $0.014 \mathrm{~mm}^{2}$.

Кроме того, был определен параметр $F_{\text {r }}$ (фактор шероховатости), который представляет собой отношение площади реальной поверхности к площади проекции $F_{\mathrm{r}}=S_{\mathrm{d}} / S_{\mathrm{p}}$, где $S_{\mathrm{d}}-$ площадь поверхности после деформации (истинная площадь поверхности), $S_{\mathrm{p}}$ - площадь горизонтальной проекции поверхности (геометрическая площадь поверхности). Физический смысл данного параметра заключается в том, что он показывает степень выраженности рельефа на поверхности, а его безразмерный характер позволяет сравнивать степень развитости рельефных образований различного масштаба независимо от степени деформации.

Для определения величины разориентации локальных областей использовался растровый электронный микроскоп Tescan Vega II LMU c EBSD-приставкой.

\section{3. Экспериментальные результаты и обсуждение}

Картина деформационного рельефа на макроуровне обусловлена кристаллографической ориентацией монокристалла. Для металлов с ГЦК-решеткой деформация в основном развивается путем сдвига по системам типа $\{111\}\langle 110\rangle$. Расположение систем скольжения и их число определяются кристаллографической ориентацией и напряженным состоянием в локальной области нагруженного кристалла. Для каждого варианта ориентации картина деформационного рельефа индивидуальна, но имеет общие закономерности для монокристаллов различных ГЦК-металлов со средним и высоким значениями энергий дефектов упаковки. Кроме того, кристаллогеометрия обусловливает величину неоднородности и характер распределения деформации [13]. Ранее авторами было показано, что распределение величины компонент деформации вдоль следов сдвига, мезои макрополос деформации носит квазипериодический характер. 

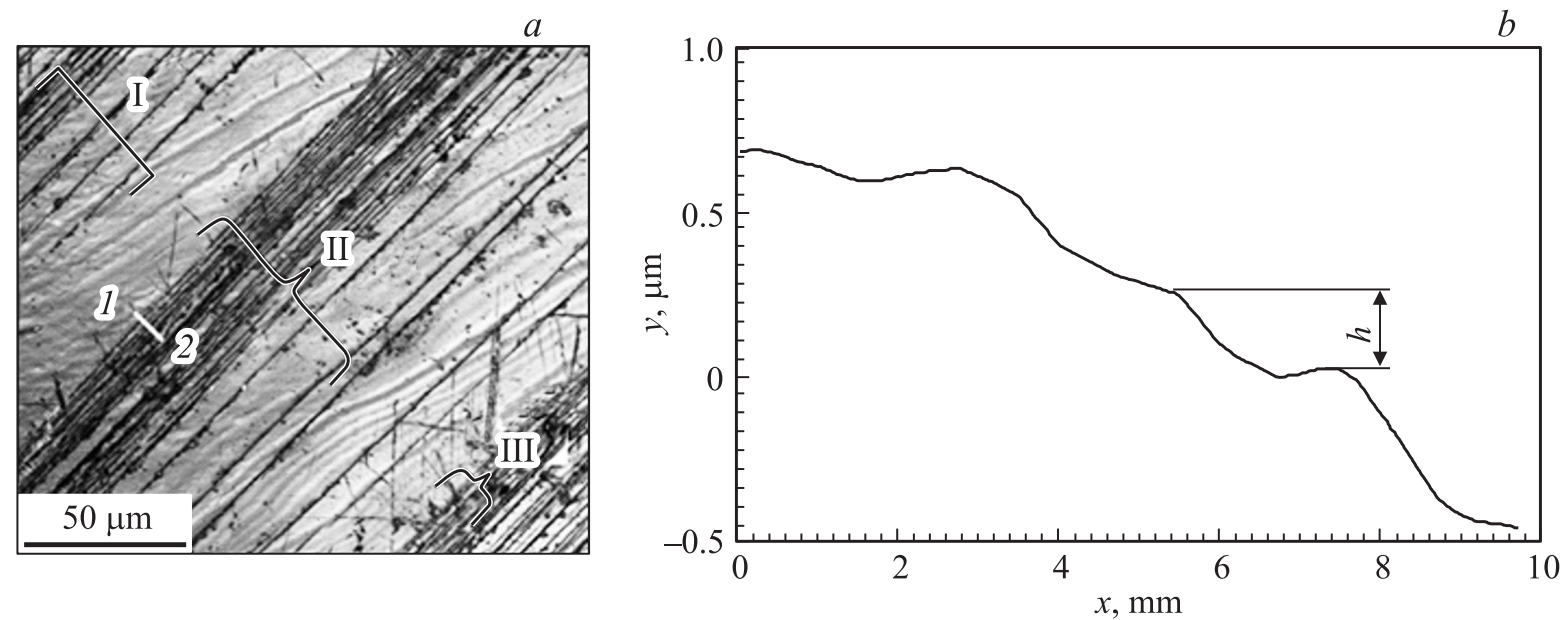

Рис. 1. Рельеф поверхности, представленный системами пачек следов I-III $(a)$, и профиль поверхности вдоль секущей $1-2(b)$.

С началом нагружения на поверхности монокристаллов любой ориентации наблюдается формирование следов сдвига, что, по сути, уже образует квазипериодический профиль поверхности. При этом образец разбивается на деформационные домены, деформация в которых организована по системам сдвига, отличающимся от систем сдвига в соседних областях кристалла. Разбиение монокристалла на домены обеспечивает макроскопическое изменение формы образца. Внутри каждого домена деформация происходит по схеме, которую отражает поле векторов смещения [14].

Анализируя экспериментальный материал по деформационному рельефу, формирующемуся на боковых поверхностях монокристаллов никеля различной кристаллографической ориентации, можно выделить следующие механизмы изменения формы поверхности посредством систем параллельных октаэдрических плоскостей.

1. Формирование групп параллельных следов скольжения (микропачки следов скольжения - следа сдвига).

2. Формирование пачек следов сдвига.

3. Формирование систем пачек следов (рис. 1).

В этих случаях образование рельефа осуществляется за счет сдвига по параллельным октаэдрическим плоскостям. След скольжения отражает результат основного механизма деформации - сдвига в плоскости скольжения. Этот элемент является базовым структурным элементом деформационного рельефа поверхности образца, посредством которого формируются элементы рельефа более высокого масштабного уровня. Следы скольжения на поверхности кристалла могут быть распределены равномерно или группироваться в пачки. Пачка следов скольжения представляет собой результат сдвига по системе параллельных октаэдрических плоскостей. Внутри пачки различаются ступени от сдвига по этим плоскостям ( $h$ на рис. $1, b)$. Суммарная величина сдвига в микропачке (следе сдвига) составляет $70-130 \mathrm{~nm}$. С учетом того, что вектор Бюргерса для никеля $b=0.249 \mathrm{~nm}$, в формировании ступени сдвига задействовано 280-550 дислокаций.

Ширина пачек следов сдвига, которые фиксируются при оптическом увеличении, может варьироваться в пределах 0.4-4.0 mm, длина - в пределах $1.0-5.0 \mathrm{~mm}$. Они формируют на поверхности области интрузии. Глубина областей интрузии 3-15 $\mu \mathrm{m}$ в зависимости от степени деформации (первое значение соответствует $3 \%$ деформации, второе - 20\%).

Системы параллельных пачек следов сдвига отражают процесс деформации в макроскопической области монокристалла. Совокупность последовательных сдвигов по различным системам параллельных плоскостей скольжения обусловливает формоизменение деформационного домена. Это зависит от кристаллографической ориентации оси сжатия и боковых граней образца.

4. Формирование мезополос.

5. Формирование системы мезополос.

Если в локальной области монокристалла действуют пересекающиеся плоскости скольжения или возможны эффекты, связанные с особенностями скольжения дислокаций (например, поперечное скольжение), то данные области на мезоуровне могут диагностироваться как мезополосы, из которых могут формироваться системы мезополос.

Системы мезополос представляют собой группу параллельных мезополос, которые развиваются в пределах деформационного домена и представляют собой области экструзии материала.

Ширина одной мезополосы составляет $0.2-1.0 \mathrm{~mm}$, длина - 1.0-5.0 mm, высота области экструзии равна $1.5-3 \mu \mathrm{m}$ в зависимости от степени деформации (первое значение соответствует 7\% деформации, второе $29 \%$ ). Система мезополос может достигать ширины до $2 \mathrm{~mm}$. Величина сдвига в мезополосе $1900-3800 \mathrm{~nm}$; следовательно, задействовано 7600-15300 дислокаций. Величина сдвига в следах, образующих мезополосу, составляет $80-300 \mathrm{~nm}$. 


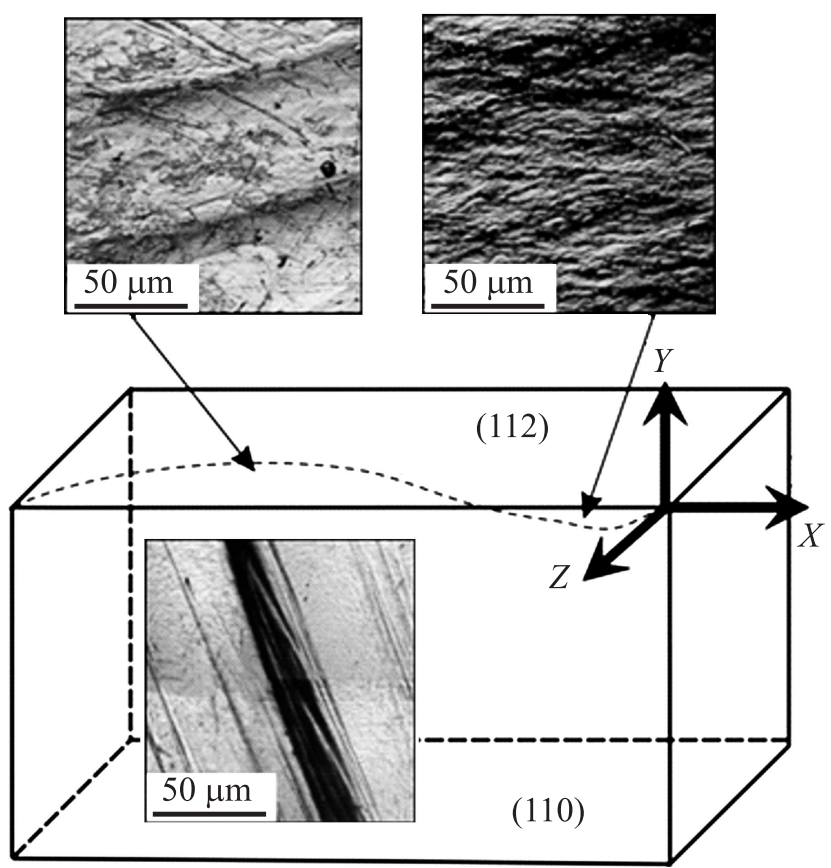

Рис. 2. Формоизменение [111]-монокристалла и характерные элементы деформационного рельефа, $\varepsilon=0.31$.

\section{6. Формирование макрополос деформации.}

Макрополосы деформации также основываются на сдвиге по параллельным октаэдрическим плоскостям. Однако в данном случае можно предположить присутствие ротационной компоненты, которая обеспечила бы закручивание следов сдвига внутри макрополосы, наблюдаемое в эксперименте (рис. 2). Это подтверждают данные EBSD-анализа (EBSD - метод дифракции обратно рассеянных электронов), полученные с поверхности образца. Анализ результатов показал небольшое размытие ориентаций относительно исходных направлений.

Макрополосы представляют собой зоны интрузии материала. Ширина одной макрополосы составляет $0.06-1.0 \mathrm{~mm}$, длина $-1.0-6.0 \mathrm{~mm}$, а глубина области интрузии равна $1.5-7 \mu \mathrm{m}$ в зависимости от степени деформации (первое значение соответствует $1.5 \%$ деформации, второе - $31 \%$ ). Величина сдвига в следах, образующих макрополосу, составляет $100-1300 \mathrm{~nm}$.

7. Формирование складок в области выпуклости.

8. Формирование складок в области вогнутости.

Складчатые структуры, развивающиеся на поверхности монокристалла, чрезвычайно разнообразны и интересы. Авторская классификация их приведена в работах $[15,16]$. Морфология складчатых структур во многом обосновывается местом их формирования. Складки формируются в приторцевых областях и в местах макроизгиба образца уже при деформации менее $5 \%$, с увеличением степени деформации доля площади грани, занятая складками, увеличивается. Обнаружено, что степень изгиба образца и характер кривизны (выпуклость- вогнутость) влияют на геометрические размеры складчатых структур и их морфологические особенности. Обнаружено, что складки различного типа образуются при совместном действии сдвига по октаэдрическим плоскостям, изгибе поверхности и переориентации локальных областей кристалла. В дополнение отметим, что складчатые структуры, формирующиеся в области вогнутости, „работают“ совместно с макрополосами разориентации на взаимно перпендикулярной грани (рис. 2).

Геометрические размеры складок в области выпуклости следующие: длина 1-3 mm, ширина $0.09-0.15 \mathrm{~mm}$; в области вогнутости $0.010-0.020 \mathrm{~mm}$ и 0.004-0.005 mm соответственно (данные для величины деформации 31\%).

Все рассмотренные выше способы организации изменения формы поверхности в процессе пластической деформации связаны с формированием квазипериодического профиля поверхности. В широком смысле все они подобны складкам, так как образованы чередованием выступов и впадин, т. е. в результате изгиба поверхности без нарушения сплошности материала.

Профиль поверхности отражает как отдельные сдвиги, так и изменение кривизны поверхности в области выделенных элементов рельефа. Для его описания использование только величины ступенек сдвига и расстояния между следами является недостаточным. Кроме того, задача имеет ряд методических трудностей. С одной стороны, трудно достаточно точно идентифицировать ступеньку сдвига на общем фоне неровностей рельефа. С другой стороны, величина сдвига не отражает корректно физику процесса, так как в рассматриваемой области она может уже измениться за счет сдвига в параллельных плоскостях скольжения. Кроме того, изменение рельефа поверхности есть результат совокупного действия сдвига по параллельным плоскостям скольжения и не обязательно только от одной системы скольжения. Поэтому представляет интерес проанализировать деформационный рельеф с использованием ряда как амплитудных, так и интегральных количественных параметров. В работе проведена двумерная и трехмерная оценка деформационного рельефа. С помощью двумерной оценки по отдельным профилям были выявлены ступени сдвига для элементов рельефа всех типов. Например, на рис. $1, b$ показана ступенька сдвига в пачке следов.

С привлечением трехмерного анализа профиля были количественно оценены структуры различного типа. Значения, определенные непосредственно внутри пачек следов сдвига, мезо- и макрополос и складок, приведены в таблице.

Арифметическое среднее высоты поверхности $S_{\text {a }}$ и среднее квадратичное значение высоты поверхности $S_{\mathrm{q}}$ являются усредненными параметрами оценки поверхности и должны использоваться в совокупности с другими параметрами для полного представления о морфологии поверхности. Можно отметить, что значения этих параметров близки для следов сдвига и макрополос, что 
Параметры деформационных структур различного типа

\begin{tabular}{l|c|l|c|c}
\hline \multicolumn{1}{c|}{ Структура } & $S_{\mathrm{a}}, \mu \mathrm{m}$ & $S_{\mathrm{q}}, \mu \mathrm{m}$ & $S_{\mathrm{sk}}$ & $S_{\mathrm{ku}}$ \\
\hline Следы сдвига & 0.517 & 0.692 & 1.05 & 0.256 \\
Мезополосы & 0.974 & 1.11 & -0.429 & -0.581 \\
Макрополосы & 0.407 & 0.538 & 1.46 & 2.47 \\
Складки в области & 1.99 & 2.29 & -0.89 & -1.12 \\
выпуклости & & & & \\
Складки в области & 2.35 & 2.67 & -0.302 & -1.23 \\
вогнутости & & & &
\end{tabular}

свидетельствует о подобном способе организации сдвига по октаэдрическим плоскостям, но не отражает индивидуальных особенностей организации рельефа внутри макрополосы, связанного с локальной переориентацией. Эти различия, однако, можно идентифицировать при анализе других параметров, приведенных в таблице и описанных далее.

Асимметрия поверхности ограниченного масштаба $S_{\mathrm{sk}}$ оценивает асимметричность функции плотности распределения ординат. Положительная асимметрия свидетельствует о доминировании высоких пиков, которые выделяются из среднего. Отрицательная асимметрия указывает на наличие гладких протяженных плато. Данный параметр можно использовать для оценки деформационной структуры на поверхности с точки зрения наличия на ней концентраторов напряжений. С физической точки зрения параметр асимметричности можно связать с эффективностью способа самоорганизации деформации в кристалле с целью сохранения целостности образца при деформировании.

В работе также было проанализировано распределение асимметрии высотного распределения профиля $R_{\mathrm{sk}}$ перпендикулярно структурным элементам рельефа различного типа (двумерный анализ). На рис. 3, $a$ показан профиль поверхности в области формирования систем пачек следов, фигурными скобками I-III отмечены зоны, соответствующие наиболее плотному расположению параллельных следов сдвига. Именно они при оптическом наблюдении воспринимаются как пачки (рис. 1,a). В целом именно для этих областей характерен положительный коэффициент асимметрии, что свидетельствует о преобладании четких высоких пиков, по-видимому, отдельных следов внутри пачки.

Эксцесс высотного распределения $S_{\mathrm{ku}}$ - это мера вершинности распределения высоты на поверхности. Благодаря этому параметру можно определить угол наклона профиля неровностей поверхности. В том случае, когда кривая плотности распределения вытянута в высоту, можно говорить о преобладании округлых невысоких неровностей, в противном случае (когда график более широкий) - о наличии глубоких острых неровностей. Из данных таблицы следует, что внутри макрополосы поверхность представляет собой чередование выступов и впадин округлой формы небольшой высоты. Вероятно, ступени, формирующие макрополосу, образованы микропачками следов скольжения от меньшего числа октаэдрических плоскостей в микропачке, чем следы сдвига или мезополосы. Такой способ самоорганизации деформации в макрополосе приводит к тому, что неоднородность деформации внутри нее не превышает величины неоднородности деформации внутри элементов рельефа другого типа, даже несмотря на стесненные условия сдвига и значительное формоизменение на макроуровне [17]. В то же время области интенсивного формирования складок на боковой грани (112) являются местом наибольшей локализации деформации, при этом мы наблюдали чередование областей растяжения и сжатия. Анализ эксцесса высотного распределения $S_{\mathrm{ku}}$ для складок показывает, что для данной зоны характерно наличие глубоких острых впадин, которые можно рассматривать как локальные концентраторы напряжений на поверхности, приводящие к неоднородности деформации.

Для оценки эффективности изменения формы поверхности посредством структурных элементов рельефа различного типа использовался фактор шероховатости $F_{\mathrm{r}}$. На рис. 4 представлена пузырьковая диаграмма, которая отражает взаимосвязь геометрических размеров (ось $X$ - длина, ось $Y$ - ширина) и степени рельефности поверхности $F_{\mathrm{r}}$ (диаметр пузырька), образованной тем или иным типом элементов рельефа. Сплошной линией обведены значения для системы (группы) элементов деформационного рельефа, штриховой - значения, характерные для отдельного элемента рельефа.

В проанализированном в работе наборе монокристаллов с различной ориентацией оси сжатия и боковых
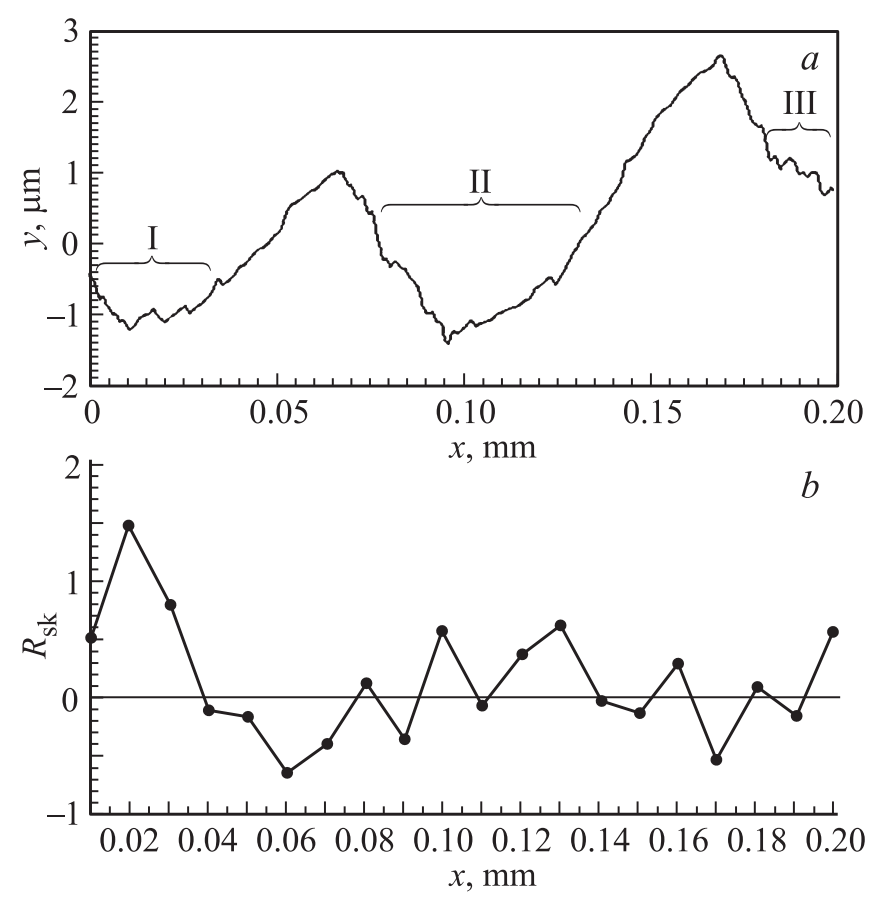

Рис. 3. Профиль поверхности в области формирования пачек $(a)$ и распределение величины $R_{\mathrm{sk}}$ вдоль профиля $(b)$. Области I-III на части $a$ соответствуют областям на рис. $1, a$. 


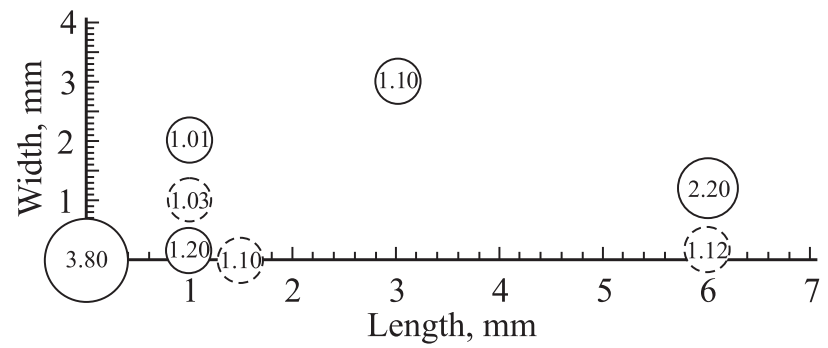

Рис. 4. Соотношение между геометрическими размерами и фактором шероховатости элементов деформационного рельефа. 1.10 - пачка плоскостей сдвига (штриховая линия), 1.10 - пачка следов (сплошная линия), 1.03 - мезополоса, 1.01 - системы мезополос, 1.12 - макрополоса, 2.20 система макрополос, 1.20 - складки в области выпуклости, 3.80 - складки в области вогнутости.

граней выделяется ориентация, в которой из-за расположения областей затрудненного сдвига (ввиду выхода октаэдрических плоскостей не на свободные боковые поверхности, а на торцы, ограниченные пуансонами испытательной машины) деформация не может быть реализована только внутридоменным скольжением по семейству октаэдрических плоскостей. Такой ориентацией является ориентация [111]. В этом случае характерные элементы рельефа на соответствующих гранях (макрополосы на грани (110) и складки на грани (112)) приводят к максимальному искривлению поверхности. Это способствует заметному увеличению степени рельефности граней, что отражается в росте параметра $F_{\mathrm{r}}$. Вместе с тем можно отметить, что в зоне вогнутости наблюдается еще большее увеличение площади поверхности после деформации, что связано со значительным локальным формоизменением в этой области кристалла за счет совместного действия на взаимно перпендикулярных гранях макрополос деформации и складок (рис. 2). Такое значительное увеличение площади поверхности (это отражается в увеличении параметра $F_{\mathrm{r}}$ ) возможно только при совместном действии сдвиговой деформации и внутрикристаллической разориентации более $2^{\circ}$.

Во всех остальных случаях реализация формоизменения внутридоменной деформации по семейству параллельных октаэдрических плоскостей без привлечения ротационной составляющей идет с минимальным изменением площади поверхности по сравнению с исходной „ровной“ недеформированной поверхностью (рис. 4). Это, по-видимому, обусловлено стремлением системы минимизировать работу сдвиговой деформации.

В связи с тем что складкообразование приводит к наибольшему увеличению площади поверхности и по способу организации складки более всего отличаются от других структурных элементов деформационного рельефа, были проведены дополнительные исследования с привлечением EBSD-анализа. Эксперименты были поставлены с целью рассмотрения особенностей протекания деформации в приповерхностном слое и в объеме [111]-монокристалла. Для этого была проведена съемка образца в области вогнутости, занятой складками, в направлении от бокового ребра в глубь материала. Съемка проводилась на грани (110), которая перпендикулярна грани, занятой складками. Далее представлено описание результатов, полученных при общей деформации монокристалла $16 \%$.

Результаты эксперимента свидетельствуют о том, что глубина проникновения складок в глубь кристалла достигает $680 \mu \mathrm{m}$. Переориентированные области наиболее ярко выделяются на глубине до 350-380 $\mu \mathrm{m}$ от поверхности. При этом углы разориентации достигают величин свыше $8-15^{\circ}$ и отмечается наибольшая доля границ разориентации с углами $2-8^{\circ}$. По мере удаления от поверхности границы с величиной разориентации более $8-15^{\circ}$ исчезают, а доля границ с величиной разориентации более $2^{\circ}$ постепенно снижается. Сопоставление полученных результатов с литературными данными [18-20] позволяет считать, что величина разориентации в $2-8^{\circ}$ набирается благодаря развитию ячеистой субструктуры, типичной для никеля при рассматриваемой степени деформации. Величина же разориентации в $8-15^{\circ}$ в приповерхностных слоях в области интенсивного складкообразования достигается за счет поворота кристаллической решетки.

\section{4. Выводы}

1. Все элементы деформационного рельефа, наблюдающиеся на поверхности, образованы сдвигом по семейству октаэдрических плоскостей. Системы сдвига в данной локальной области монокристалла обусловливают проявление рельефа поверхности, воспринимаемого (при оптическом наблюдении) как отдельные его структурные элементы.

2. Показана возможность использования дву- и трехмерных параметров шероховатости для описания локальных особенностей сдвиговой деформации, формирования областей экструзии и интрузии материала.

3. Фактор шероховатости $F_{\mathrm{r}}$ указывает на эффективность изменения формы локальных участков боковой грани при определенной организации сдвига (формирование элементов деформационного рельефа различного типа). В тех случаях, когда организации деформации сопутствует заметное увеличение площади поверхности (большее значение $F_{\mathrm{r}}$ ), это сопровождается переориентацией кристаллического объема материала.

4. Сопоставление результатов настоящей работы с величиной локальной деформации, полученной авторами ранее, позволило установить, что общие принципы самоорганизации сдвиговой деформации не приводят к заметной ее локализации. Увеличению локализации деформации способствуют несовместность деформации и величина разориентации соседних деформационных доменов. 


\section{Список литературы}

[1] Z. Zhao, R. Radovitzky, A. Cuitino. Acta Mater. 52, 5791 (2004).

[2] O. Zinovieva, V. Romanova, R. Balokhonov, A. Zinoviev, Zh. Kovalevskaya. J. Appl. Math. Phys. 2, 425 (2014).

[3] O. Wouters, W.P. Vellinga, R. Van Tijum, J.Th.M. de Hosson. Acta Mater. 53, 4043 (2005).

[4] B. Meng, M.W. Fu. Mater. Design 83, 400 (2015).

[5] N.J. Wittridge, R.D. Knutsen. Mater. Sci. Eng. A 269, 205 (1999).

[6] S. Khoddam, H. Beladi, P.D. Hodgson, A. Zarei-Hanzaki. Mater. Design 60, 146 (2014).

[7] В.В. Губернаторов, Б.К. Соколов, И.В. Гервасьева, Л.Р. Владимиров. Физ. мезомеханика 2, 1-2, 157 (1999).

[8] В.Е. Панин, А.В. Панин. Физ. мезомеханика 8, 5, 7 (2005).

[9] А.В. Панин, В.А. Романова, Р.Р. Балохонов, О.Б. Перевалова, Е.А. Синякова, О.С. Емельянова, М.В. ЛеонтьеваСмирнова, Н.И. Карпенко. Физ. мезомеханика 14, 4, 57 (2011).

[10] П.В. Кузнецов, Ю.И. Тюрин, И.П. Чернов, Т.I. Sigfusson. ФTT 54, 2302 (2012).

[11] Д.В. Лычагин, Е.А. Алфёрова, А.С. Тайлашев. Изв. вузов. Физика 58, 5, 119 (2015).

[12] D.V. Lychagin, E.A. Alfyorova. Appl. Mech. Mater. 379, 66 (2013).

[13] Д.В. Лычагин, Е.А. Алфёрова, Р.В. Шаехов, А.Д. Лычагин, В.А. Старенченко. Фундам. пробл. соврем. материаловедения 4, 2, 26 (2007).

[14] V.V. Kibitkin, A.I. Solodushkin, V.S. Pleshanov, D.V. Lychagin. Optoelectron. Instrum. Data Proc. 47, 83 (2011).

[15] Д.В. Лычагин, Е.А. Алфёрова. ФТТ 57, 1981 (2015).

[16] D.V. Lychagin, S.Yu. Tarasov, A.V. Chumaevskii, E.A. Alfyorova. Appl. Surf. Sci. 371, 547 (2016).

[17] Д.В. Лычагин, Е.А. Алфёрова, В.А. Старенченко. Физ. мезомеханика 13, 3, 75 (2010).

[18] В.А. Старенченко, Д.В. Лычагин, Р.В. Шаехов, Э.В. Козлов. Изв. вузов. Физика 7, 71 (1999).

[19] B.J. Duggan, M. Hatherly, W.B. Hutchinson, P.T. Wakefield. Met. Sci. 12, 343 (1978).

[20] A.A. Ridha, W.B. Hutchinson. Acta Met. 30, 1929 (1982). 